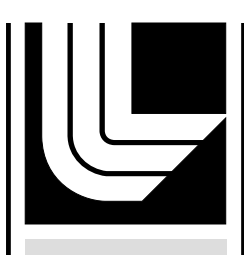

LAW RENCE LIVERMORE N A T IO N A L LABORATORY

Mass by Energy Loss

Quantitation as a Practical

Sub-Microgram Balance

M. Palmblad, G. Bench, J. S. Vogel

October 18, 2004

Analytical Chemistry 
This document was prepared as an account of work sponsored by an agency of the United States Government. Neither the United States Government nor the University of California nor any of their employees, makes any warranty, express or implied, or assumes any legal liability or responsibility for the accuracy, completeness, or usefulness of any information, apparatus, product, or process disclosed, or represents that its use would not infringe privately owned rights. Reference herein to any specific commercial product, process, or service by trade name, trademark, manufacturer, or otherwise, does not necessarily constitute or imply its endorsement, recommendation, or favoring by the United States Government or the University of California. The views and opinions of authors expressed herein do not necessarily state or reflect those of the United States Government or the University of California, and shall not be used for advertising or product endorsement purposes. 


\title{
Mass by Energy Loss Quantitation as a Practical Sub-Microgram Balance
}

\author{
Magnus Palmblad*, Graham Bench and John S. Vogel \\ Center for Accelerator Mass Spectrometry, Lawrence Livermore National Laboratory, \\ Livermore, California 94551-0808, United States \\ * corresponding author: (fax) +1-925-423-7884; (e-mail) palmblad1@llnl.gov
}




\begin{abstract}
A simple device integrating a thin film support and a standard microcentrifuge tube can be used for making solutions of accurately known concentration of any organic compound in a single step, avoiding serial dilution and the use of microgram balances. Nanogram to microgram quantities of organic material deposited on the thin film are quantified by ion energy loss and transferred to the microcentrifuge tube with high recovery.
\end{abstract}


Milligram and microgram balances are found in almost every chemical and biological laboratory. Microgram balances in particular are sensitive devices requiring a stable environment and frequent calibration. We have previously shown that nanogram to microgram quantities of organic material deposited on thin $\mathrm{SiN}$ films can be accurately quantified for mass by energy loss quantitation (MELQ) using an inexpensive and commercially available alpha spectrometer and a ${ }^{210} \mathrm{Po}$ alpha particle source [1]. In MELQ, the energy loss of megaelectron volt (MeV) ions passing through a deposited and dried sample is used to calculate the average areal density using tabulated stopping powers of the ions. The sample mass is easily calculated from the known projected area. We use an average elemental composition for an organic material in an automated algorithm, which is sufficiently accurate for most organic compounds and biological samples [1]. Importantly, the method could be fully automated, mimicking a common laboratory balance (sample in - mass out). The measurement throughput is limited by the ion source and required precision, typically $10-15 \mathrm{samples} / \mathrm{h}$. The dynamic range also depends on the thickness and uniformity of the substrate and on instrumental parameters, such as the detector's energy resolution. For MELQ measurements, which are based on a small shift in energy due to the sample, the substrate onto which the sample is deposited should be as thin and as uniform as possible. The lower limit-of-quantitation is, to a first approximation, inversely proportional to the area of the sample. Nanogram to several picograms of material in a small area can be quantified by MELQ using a focused ion beam [2]. 
A simple device integrating the thin film support and a standard microcentrifuge tube was designed to make solutions of known concentration of an arbitrary compound in a single step, avoiding serial dilution and the use of sensitive microgram balances. Microgram quantities of organic material in 0.5-2 $\mu 1$ are deposited on the inside of a $2.54 \mu \mathrm{m}$ Mylar $^{\circledR}$ (polyester) film (SPI Supplies, West Chester, PA) bonded flush with the lid of a $1.5 \mathrm{ml}$ microcentrifuge tube (Eppendorf AG, Hamburg, Germany) using 3M${ }^{\mathrm{TM}}$ Hi-Strength Spray Adhesive 90 (3M, St. Paul, MN) after drilling a $5 \mathrm{~mm}$ diameter hole through the center of the lid (Figure 1). The sample is quantified by alpha particle energy loss using a commercially available alpha spectrometer (Ortec Soloist, Ortec Instruments, Oak Ridge TN) and a $0.1 \mu \mathrm{Ci}^{210} \mathrm{Po} 5.304 \mathrm{MeV}$ source (Spectrum Techniques, Oak Ridge, TN). The lid provides the necessary supporting frame for the thin Mylar ${ }^{\circledR}$ film and transfers the sample directly to the microcentrifuge tube (Figure 1). The use of a hydrophobic film increases the sensitivity up to tenfold, as aqueous samples are concentrated in a small area limited by the contact area between the sample droplet and the hydrophobic surface.

The useful mass range with the $2.54 \mu \mathrm{m}$ Mylar $^{\circledR}$ and a $2.5 \mathrm{~mm}$ collimator is $0.25-100 \mu \mathrm{g}$. This is somewhat less sensitive than the thinner SiN windows [1], but physically more robust and significantly less expensive. SiN membranes do not work well with organic solvents commonly used in solid phase extraction and other purification techniques, as these solvents makes large contact areas with the SiN. Three $0.5 \mu \mathrm{g}$ (nominally) aliquots of glycine (Sigma-Aldrich, St. Louis, MO) deposited in $1 \mu 150 \%$ ACN on $2.54 \mu \mathrm{m}$ Mylar ${ }^{\circledR}$ measured $0.59 \pm 0.01 \mu \mathrm{g}$. The standard deviation of the mass measured on blank 
$2.54 \mu \mathrm{m}$ Mylar $^{\circledR}$ substrates after deposition of $1 \mu 1 \mathrm{H}_{2} \mathrm{O}$ is $\sim 50 \mathrm{ng}$ using the $2.5 \mathrm{~mm}$ diameter collimator, corresponding to $0.4 \%$ of the $13.3 \mu \mathrm{g}$ projected Mylar ${ }^{\circledR}$ mass.

To measure recovery from the thin film, equal $1 \mu \mathrm{l}$ droplets of $1.5,7.5$, and $15 \mu \mathrm{g} / \mu \mathrm{l}$, and $2 \times 1 \mu 115 \mu \mathrm{g} / \mu \mathrm{l}$ myoglobin from horse skeletal muscle (Sigma-Aldrich) were deposited directly into microcentrifuge tubes and onto the Mylar ${ }^{\circledR}$ lids. The latter were quantified by MELQ and resuspended in $200 \mu 1 \mathrm{H}_{2} \mathrm{O}$. The absorbance in the Soret band ( 408 nm) was measured using a Shimadzu UV-2101PC spectrophotometer (Shimadzu, Kyoto, Japan) and a $200 \mu \mathrm{l}$ microcuvette (Figure 2). The MELQ measurements show better linearity in the $0-30$ microgram range and better precision for the smallest samples, whereas the absorbance measurement is somewhat more precise for the larger masses. The total recovery of myoglobin, including transportation and MELQ measurement, was better than $90 \%$ when resuspending by a few seconds of rapid shaking in $\mathrm{H}_{2} \mathrm{O}$. The recovery and optimal method for resuspension likely differ depending on the analyte and solvent used.

The illustrated device is ideal for making up solutions of known concentration of any organic compound in a single step, avoiding possibly inaccurate and wasteful serial dilutions and the use of delicate microgram balances. The alpha spectrometer compares favorably in price and footprint to microgram balances and could be made to operationally mimic a balance with the integration of the spectrometer and dedicated software. The algorithm used for converting energy spectra to sample masses is available from the authors. 


\section{ACKNOWLEDGEMENTS}

This work was supported by the NIH/NCRR RR-13461 and performed in part under the auspices of the U.S. Department of Energy by University of California Lawrence Livermore National Laboratory under Contract No. W-7405-ENG-48.

\section{REFERENCES}

1. Grant, P. G.; Palmblad, M.; Murov, S.; Hillegonds, D. J.; Ueda, D. L.; Vogel, J. S.; Bench, G. Anal Chem 2003, 75, 4519-4524.

2. Lefevre, H. W.; Schofield, R. M.; Overley, J. C.; MacDonald, J. D. Scanning Microsc 1987, 1, 879-889. 


\section{FIGURES}

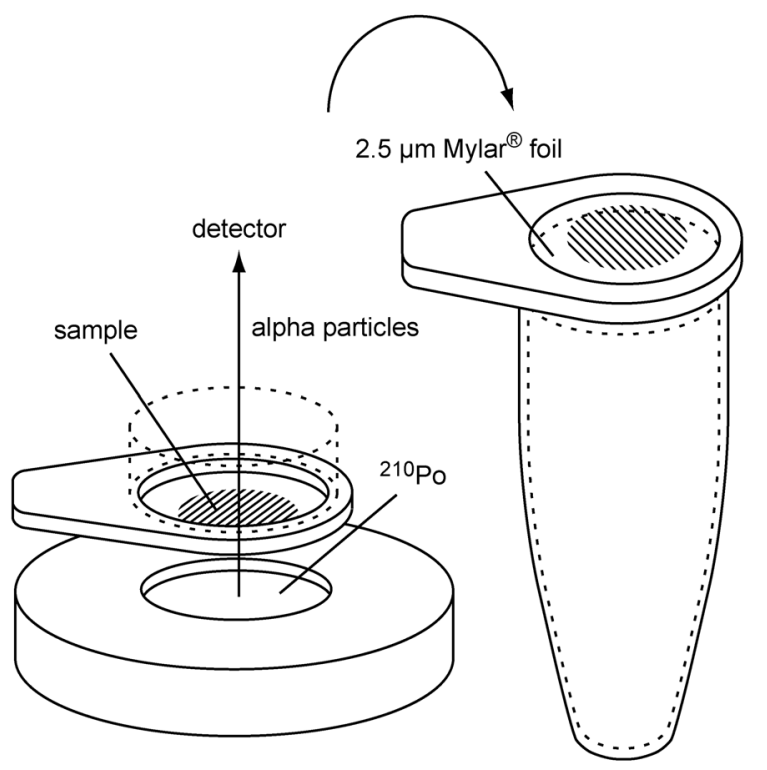

Figure 1. A sample is deposited in $0.5-2 \mu 1$ solution onto a $2.54 \mu \mathrm{m}$ Mylar ${ }^{\circledR}$ film bonded to the top of lid of the microcentrifuge tube, dried and measured by MELQ. The sample rests on a metal plate with a $2.5 \mathrm{~mm}$ diameter centered collimator during measurement (omitted for clarity). The lid subsequently transfers the sample into the tube. 


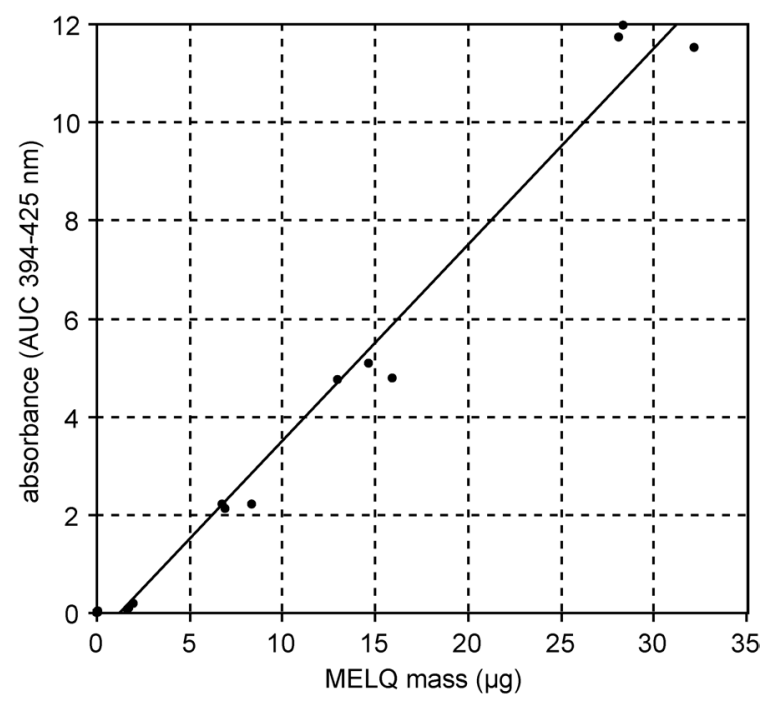

Figure 2. The 1.5, 7.5, 15 and $30 \mu \mathrm{g}$ nominal masses are well within the linear range $\left(\mathrm{R}^{2}=0.9998\right)$ of MELQ (measuring 1.6 $\pm 0.3,7.4 \pm 0.9,14.6 \pm 1.5$, and $29.6 \pm 2.3 \mu \mathrm{g}$ respectively), the same samples resuspended in $200 \mu 1 \mathrm{H}_{2} \mathrm{O}$ had a superlinear response in the spectrophotometer $\left(\mathrm{R}^{2}=0.9913\right)$. The scatter is also due to the initial droplet deposition. 